\title{
SIMULATION OF INNOVATIVE BUSINESS CASES FOR HOUSEHOLD CUSTOMERS IN THE GERMAN ELECTRICITY SUPPLY
}

\author{
Anton GERBLINGER \\ Hochschule Augsburg - Germany \\ anton.gerblinger@hs-augsburg.de
}

\author{
Michael FINKEL \\ Hochschule Augsburg - Germany \\ michael.finkel@hs-augsburg.de
}

\author{
Rolf WITZMANN \\ TU München - Germany \\ rolf.witzmann@tum.de
}

\begin{abstract}
The scope of this paper is to show the challenges within the German electricity residential market based on an electricity price analysis since 1990. On this basis, three business models are introduced: Status Quo, Energy Contracting and Capacity Tariff. Furthermore, a simulation environment named GENESIS will be presented, in which the business models have been simulated and economic impacts of the individual actors of the German electricity supply have been analysed.
\end{abstract}

\section{INTRODUCTION}

In the German electricity supply a rigid tariff system is used for household customers. Neither flexible customer behaviour nor a reasonable usage of stochastic feed-in of renewable energies can be implemented economically. Therefore, it is currently not possible to include the customer as active participant into the energy market like it is required in [1]. The development of the electricity price stands also in contrast with this thinking (Figure 1). Until 1998 , there was an integrated energy utility company as well as the state institutions. After the liberalisation of the energy market in 1998 the energy utility company was separated into supplier, distribution system operator (DSO) and metering operator / data collector (MOP/DC).

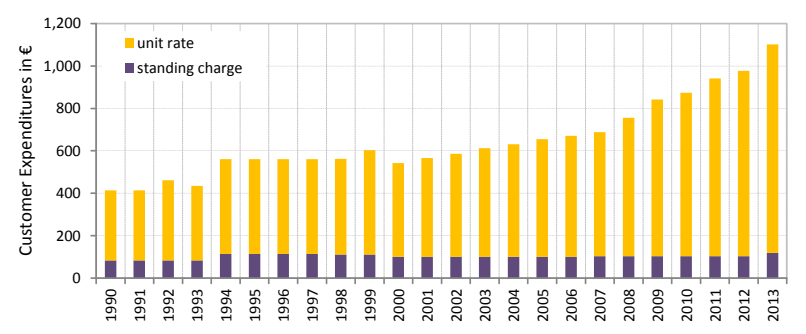
Year

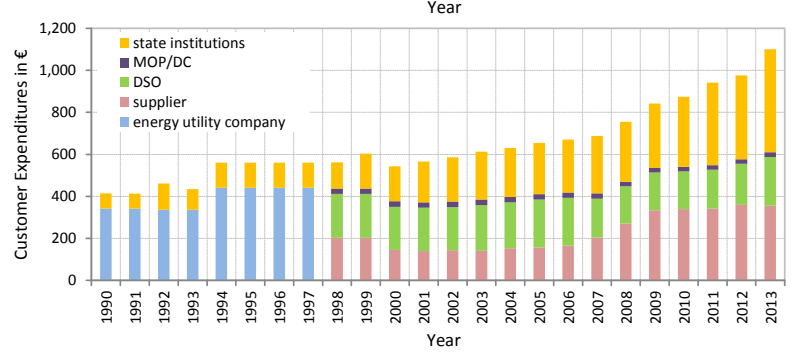

Figure 1: Customer expenditures of an average household in Germany with an electricity consumption of $3,500 \mathrm{kWh}$ $[2,3,4,5]$
In this shared market, the total expenditures for electricity energy of an average private household in Germany with $3,500 \mathrm{kWh}$ have more than doubled since the year 2000 . Related to the year 1990, the total price increase results in round about 266 per cent. This corresponds to an average electricity price increase of over 7 per cent per year within the last 23 years.

The development of the electricity prices and production costs of photovoltaic systems or rather the declining feed-in tariffs (FITs) resulted in the point of grid parity during the year 2012 [6]. Thus, it is more economical for private plant operators to use their own generated electricity instead of feeding into the distribution grid. Furthermore, the usage of battery systems is going to be more economical because of the increasing self-consumption in this sense. These investment considerations are additionally supported by tax savings. All these developments result in more and more self-consumption and, therefore, in less electricity energy usage from the public electricity grid. This explains that the revenues of the electricity price actors are going to decline dramatically because the major portion of the electricity costs are based on the used kilowatt hour (Figure 1). The actors of the electricity price get the challenge to develop new business models to be able to economise sustainably. All in all, the residential market of electrical energy is located on a spiral accelerating by itself, which makes it indispensable to change the current tariffs corresponding to the above mentioned challenges.

\section{BUSINESS MODELS}

On this basis, two innovative business models named Energy Contracting (EC) and Capacity Tariff (CT) have been developed. In order to have a common reference for these models the current tariff system was considered as the third business model named Status Quo (SQ). The business models are categorised by two customer types. The first is the Consumer (C) which represents a regular private household customer. The second customer type is named Prosumer $(\mathrm{P})$ and affects his electricity household actively by a renewable energy plant.

\section{Status Quo}

The Consumer in the Status Quo (SQ-C) has a supply contract with his supplier, which is composed of a standing charge in euro per year and a unit rate in cent per $\mathrm{kWh}$ (Figure 2). 


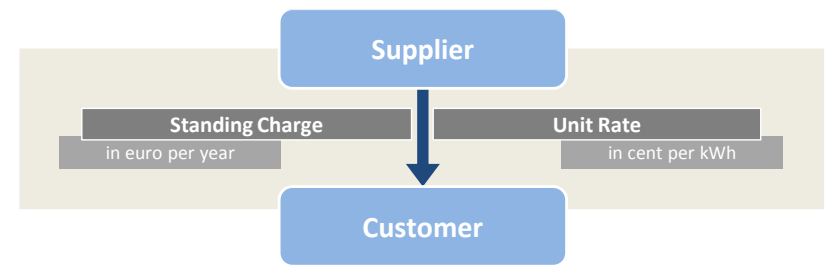

Figure 2: Current tariff model for a Consumer (SQ-C)

The unit rate represents the major portion of the customer expenditures. The components of the supply contract are detailed in the following formulas:

$$
\begin{aligned}
\text { Standing charge }= & \text { Supplier Part }+ \text { Grid Usage }+ \text { Billing } \\
& + \text { Measurement }+ \text { Meter }+ \text { VAT }
\end{aligned}
$$

Unit Rate $=$ Supplier Part + CHP-Levy + EEG-Levy

$$
\begin{aligned}
& + \text { Offshore-Levy }+ \text { Concession Fee } \\
& + \text { Electricity Tax }+ \text { Grid Fee } \\
& +\$ 19 \text { StromNEV Surcharge }+ \text { VAT }
\end{aligned}
$$

The offshore-levy is intended as an additional charge on the grid fee for the end consumers in German electricity supply, in accordance to a revision of section $17 \mathrm{f}$ paragraph 5 German Energy Industry Act (EnWG) [4].

In case of a Prosumer in the Status Quo (SQ-P) the customer has two different contracts (Figure 3). First of all, like in the SQ-C-Model, a contract of supply with his supplier, regarding his grid usage. The second tariff is a FIT with the local DSO, in which a fixed payment per kilowatt hour is established.

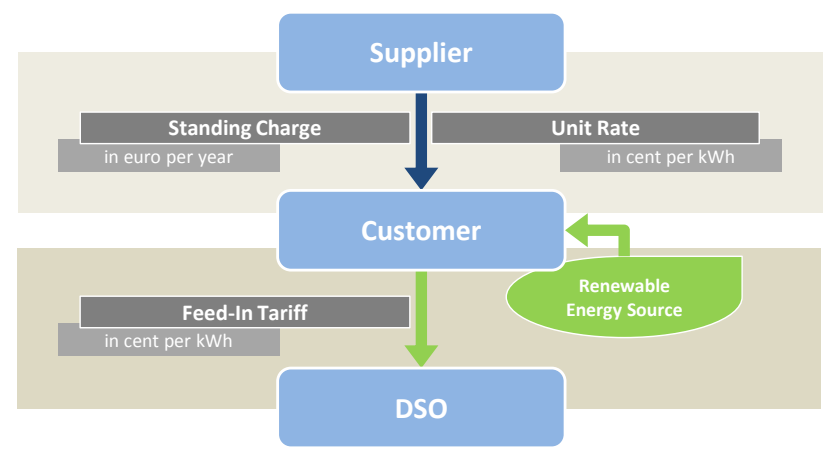

Figure 3: Current tariff model for a Prosumer (SQ-P)

The Prosumer has also the possibility of self-consumption to feed-in additionally. The price of the self-consumed kilowatt hour depends on the legal person of the plant operator. If the plant operator is an entrepreneur and therewith able to take tax benefits, the self-consumption is subjected to the VAT. The self-consumption is exempt from charges if the plant operator is a private person in legal accordance.

\section{Energy Contracting}

The first innovative business model is the Energy Contracting (EC), whose concept is already known from the heat energy market.
There, the change of an energy supplier to an energy provider is performed.

The supplier operates a renewable energy source which is installed at the customer. Thereby, the customer is partly supplied with electrical energy by his own plant, which is run by the supplier. The customer, who has to be a Prosumer in this business model, finds himself in a comfort contract with the supplier, in which grid purchase, the renewable energy direct purchase and also the leasing of the renewable energy source are settled (Figure 4). The customer remains the owner of the renewable energy source and gives off only the operation or rather the assembling and maintenance to the supplier. The customer as the plant owner receives leasing receipts from the supplier. Due to the continuous leasing receipts, the customer is an entrepreneur and can therefore claim tax advantages. This business model also offers the possibility for the DSO to influence the renewable energy source, for which the DSO is obligated to pay a levy to the supplier. Via contract the supplier offers one standing charge and two different unit rates to the customer. The first unit rate represents the costs for the kilowatt hour, which is purchased from the grid and which, with the standing charge, constitutes the supply contract like in the SQ-C-Model.

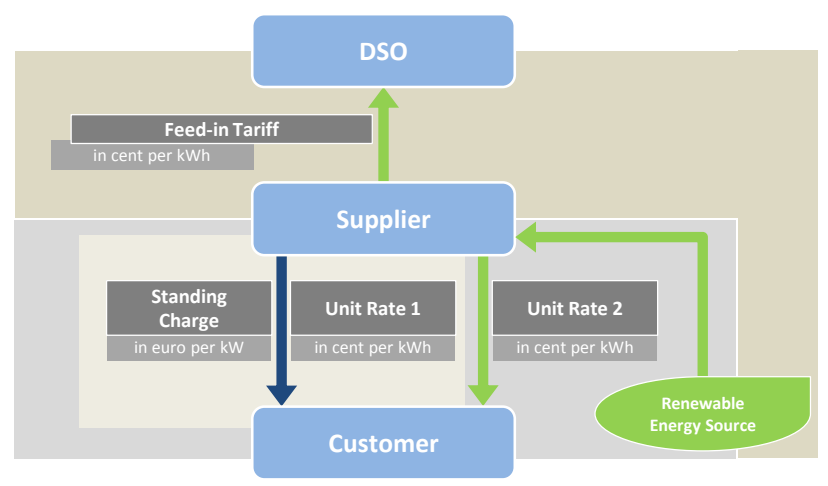

Figure 4: Tariffs of the Energy Contracting-Model (EC-P)

The second unit rate refers to the direct consumption of the renewable energy source. Due to the lower tax and levy charging, the unit rate 2 can be offered at lower price than the unit rate 1 . The supplier has the FIT with the local DSO because of its operator status. The components of the unit rate 2 are detailed in the following formula:

Unit Rate 2 = Supplier Part + EEG-Levy + VAT

For the unit rate 2 neither grid nor concession fee are incurred because of the none-take-up of the public electricity grid. CHP-levy, offshore-levy and the $\S 19$ StromNEV surcharge are interpreted as a surcharge of the grid fee and that is why these are not discharged in this case. According to section 9 paragraph 1 German Electricity Tax Act (StromStG), no electricity tax must be paid for electricity from an electricity grid which is exclusively fed in by renewable energies. 
Therefore, the unit rate 2 includes no electricity tax. In this unit rate only the VAT and the EEG-levy have to be discharged according to section 37 paragraph 3 German Renewable Energy Source Act (EEG) [7].

\section{Capacity Tariff}

The way from a "working world" that is characterised by kilowatt hours to a "power world" that is based on kilowatts is described in the second business model [8]. The major portion of customer expenditures do not consist of energy costs, like in the SQ-Model, but of the actually demand set up power. On the one hand, this becomes necessary due to the increased self-consumption percentage and on the other hand because of the further increasing role of the power as an influenceable magnitude in the smart grid [9].

In case of a Consumer (CT-C) the tariff is assembled by two rates (Figure 5). The first is a capacity charge in euro per $\mathrm{kW}$ which allocates the actual demand set up power of the connection user. Compared with the SQ-Model the second part is a substantially reduced unit rate in cent per $\mathrm{kWh}$, which still refers to the energy consumption of the customer.

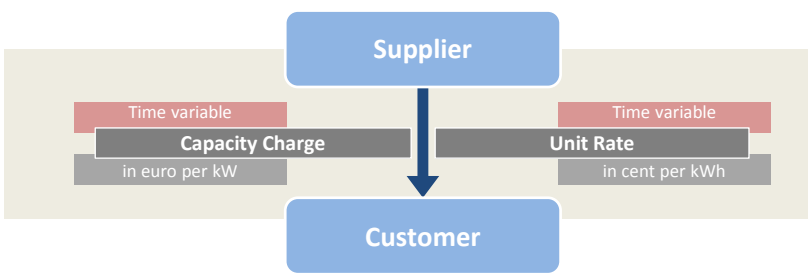

Figure 5: Capacity Tariff for a Consumer (CT-C)

The components of the capacity price and the unit rate are detailed in the following formulas:

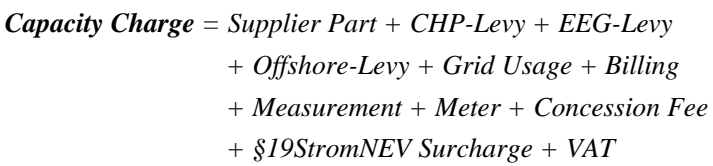

Unit Rate $=$ Supplier Part + Electricity Tax + VAT

The electricity tax is still included within the unit rate by the state institutions because of the intended impact of energy efficiency of this component. Both capacity charge and unit rate are variable in time to provide incentives for production-oriented consumption throughout the day. In order to keep the model simple, two time zones have been realized. Every component of capacity charge and unit rate is modifiable by a factor by the respective actor. The first time zone is from midnight to 11.00 a.m. and from 4.00 p.m. to midnight. Consequently, the second time zone is between 11.00 a.m. and 4.00 p.m.. The SQ-Model has been used as a starting base for this business model.

In case of a Prosumer (CT-P) the CT-C-Model is supplemented in the sense that also the feed-in capacity is considered for the capacity charge (Figure 6).

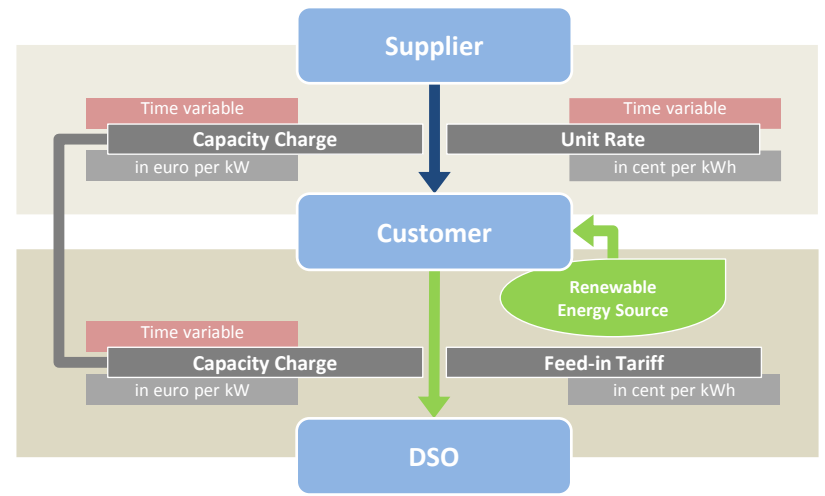

Figure 6: Capacity Tariff for a Prosumer (CT-P)

The actual maximum, which is fundamental for the capacity charge, will be subsequently determined by the maximum of consumption and feed-in. The renewable energy which is fed into the distribution grid is still remunerated under the EEG.

\section{SIMULATION ENVIRONMENT GENESIS}

A simulation environment named GENESIS was developed to evaluate the corresponding business models for all actors. Under this amendment, the business models SQ, EC and CT were developed by using the Software CONSIDEO MODELER. The models are simulated on guidelines by the legislator and the energy system (Figure 7).

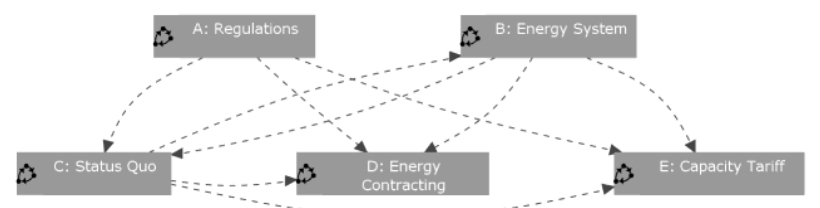

Figure 7: Overview of the main functions realized in GENESIS

Furthermore, in GENESIS it is possible to perform sensitivity analyses and takes conclusions for the business models and their actors.

\section{FRAMEWORK CONDITIONS}

The parameters considerations below are variably adjustable within the simulation environment and merely represent an example in their dimensions. The simulation period was therefore defined from 2013 to 2032. The residential customer was determined with an average electricity energy consumption of 3,500 kWh per year. In case of a Prosumer a photovoltaic system with $4 \mathrm{~kW}$ as well as a battery system with a capacity of $4.6 \mathrm{kWh}$ and a calculated service life of 20 years were additionally specified. Due to this combination a self-consumption percentage of 60 percent was chosen. The annual price increase of the unit rate was fixed on 6 percent. This growth rate in turn, defines the rates of increase of all components of the electricity price by using a special distribution key. 


\section{BUSINESS CASES}

The revenues and expenditures for each actor and every business model were simulated in GENESIS according to the above mentioned parameters. The pool of actors consisted of customer, supplier, DSO, state institutions and MOP/DC. The diagrams show the economical result for each actor in every business model as accumulated curves over 20 years.

The customer has in the SQ-C-Case total expenditures over 20 years of almost EUR 39,000 (Figure 8). The customer expenditures take about the same development in the CT-C-Case because the SQ-Model is used as a reference base for the CT-Model. The little deviation between the SQ-C-Case and the CT-C-Case is based on the additional time variability of the CT-Model.

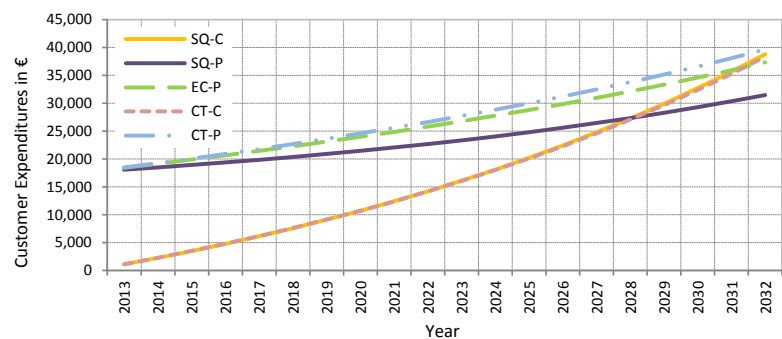

Figure 8: Customer expenditures in euro for all business cases

In case of a Prosumer the expected date of amortization for the customer in the SQ-P-Case will appear in 2028. In the EC-P-Case this point will be reached in 2031. Both amortization times are very late because of the currently high investment costs of battery systems. Within the CT-PCase the customer has still the regular consumption as well as feed-in behaviour and do not conduct these according to the capacity incentives of this business model. Therefore, the amortization of the investment costs is not possible in this case.

As far as the revenues of the actors of the electricity price concerned, the supplier will serve as an example for all actors (Figure 9). The purchasing costs of the supplier are included in his revenues. As expected, the highest revenues of the supplier were recorded in the cases of SQ-C and CT-C because of the high amount of energy that has been sold.

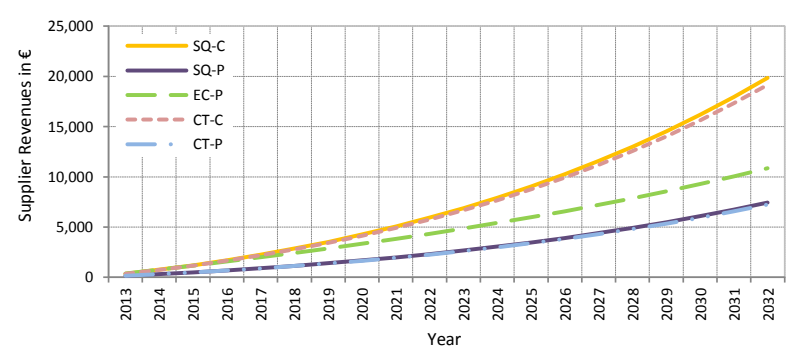

Figure 9: Supplier revenues in euro for all business cases
In contrast, the supplier has the lowest revenue situation in the SQ-P-Case because of the reduced quantity of energy that was delivered through the distribution grid. The CT-P curve rises in a similar way to that because of the reference to the SQ-P-Case. The reduced revenues of the described Prosumer models have increased significantly within the EC-P-Case.

\section{CONCLUSIONS}

The EC - and CT -Model were presented as wise business models approaches to solve the challenges of the residential electricity market. As far as the simulation results have shown, the simulation environment GENESIS is an adequate tool to simulate and evaluate corresponding business models.

Further sensitive analysis will offer more findings about the business models as well as the simulation environment. Therewith, the innovative business model approaches will be developed to a sustainable and viable solution for all actors in the residential electricity market.

\section{REFERENCES}

[1] Bundesnetzagentur, 2011, "Smart Grid und Smart Market", Eckpunktepapier der Bundesnetzagentur zu den Aspekten des sich verändernden Energieversorgungssystems, Bonn

[2] LEW Verteilnetz GmbH, 1998-2013, price sheets of grid usage and metrology, Augsburg

[3] LEW AG, 1990-2013, tariff sheets of the general tariff named LEW [Grundversorgung Privat], Augsburg

[4] TSOs, 2013, "EEG / KWK-G", Informationsplattform der deutschen Übertragungsnetzbetreiber, www.eeg-kwk.net

[5] Bundesverband der Energie- und Wasserwirtschaft e.V., 2012, "Erneuerbare Energien und das EEG: Zahlen, Fakten, Grafiken (2011)", Foliensatz zur Energie-Info

[6] Verband der Bayerischen Energie- und Wasserwirtschaft e.V., 2012, "Vom Verbraucher zum Prosumer - Auswirkungen auf das Geschäftsmodell für Versorger"

[7] I. Mikesic; H. Thieme et al, 2012, "Juristische Prüfung der Befreiung der Eigenerzeugung von der EEG-Umlage nach $\S 37$ Absatz 1 und 3 EEG", Kurzgutachten

[8] H. Wiechmann, 2012, "Die Smarte Energiewelt aus wettbewerblicher Sicht - Ein Zusammenspiel aus Smarten Kunden, Smart Market und Smartem Netz", VDE-Kongress Smart Grid, Stuttgart

[9] Bundesverband der Energie- und Wasserwirtschaft e.V., 2012, "Eckpunkte einer neuen Netzentgeltsystematik", Stellungnahme, Berlin 